Pholani Manana, Jarryd Cuthbertson, Eric C. Hosten and Richard Betz*

\title{
The crystal structure of 2,6-difluorophenol, $\mathrm{C}_{6} \mathrm{H}_{4} \mathrm{~F}_{2} \mathrm{O}$
}

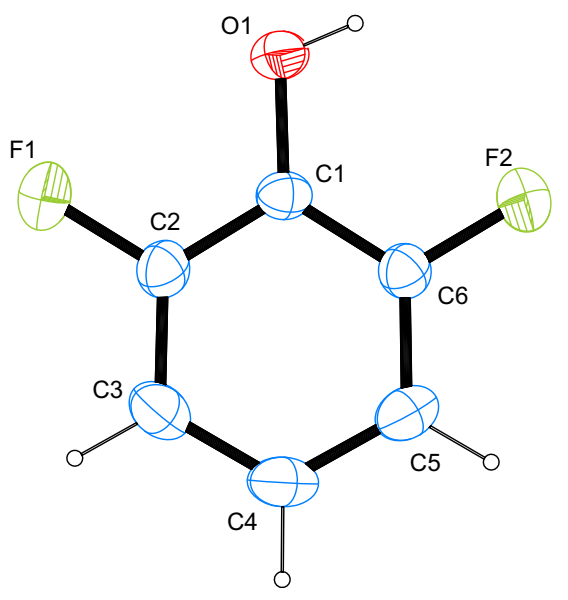

https://doi.org/10.1515/ncrs-2020-0432

Received August 3, 2020; accepted September 28, 2020; published online October 2, 2020

\begin{abstract}
$\mathrm{C}_{6} \mathrm{H}_{4} \mathrm{~F}_{2} \mathrm{O}$, orthorhombic, $P 2_{1} 2_{1} 2_{1}$ (no. 19), $a=4.9287(5) \AA$, $b=10.1752(8) \AA, c=10.9156(10) \AA, V=547.42(9) \AA^{3}, Z=4$, $R_{g t}(F)=0.0248, w R_{\text {ref }}\left(F^{2}\right)=0.0705, \mathrm{~T}=200 \mathrm{~K}$.
\end{abstract}

\section{CCDC no.: 2025946}

The molecular structure is shown in the figure. Table 1 contains crystallographic data and Table 2 contains the list of the atoms including atomic coordinates and displacement parameters.

\section{Source of material}

The compound was obtained commercially (fluorochem). Crystals suitable for the diffraction studies were obtained

*Corresponding author: Richard Betz, Department of Chemistry, Nelson Mandela University Summerstrand, Campus (South), University Way, Summerstrand, PO Box 77000, Port Elizabeth, 6031, South Africa, E-mail: Richard.Betz@mandela.ac.za. https://orcid. org/0000-0002-5730-2152

Pholani Manana, Jarryd Cuthbertson and Eric C. Hosten, Department of Chemistry, Nelson Mandela University, Summerstrand Campus (South), University Way, Summerstrand, PO Box 77000, Port Elizabeth, 6031, South Africa. https://orcid.org/0000-0003-41732550 (E.C. Hosten)
Table 1: Data collection and handling.

\begin{tabular}{|c|c|}
\hline Crystal: & Colourless block \\
\hline Size: & $0.54 \times 0.52 \times 0.48 \mathrm{~mm}$ \\
\hline Wavelength: & Mo $K \alpha$ radiation $(0.71073 \AA$ ) \\
\hline$\mu:$ & $0.15 \mathrm{~mm}^{-1}$ \\
\hline $\begin{array}{l}\text { Diffractometer, scan mode: } \\
\theta_{\max }, \text { completeness: }\end{array}$ & $\begin{array}{l}\text { Bruker APEX-II, } \varphi \text { and } \omega \\
28.4^{\circ},>99 \%\end{array}$ \\
\hline$N(h k l)_{\text {measured }}, N(h k l)_{\text {unique, }}, R_{\text {int }}:$ & $5425,1357,0.014$ \\
\hline Criterion for $I_{\mathrm{obs}}, N(h k l)_{\mathrm{gt}}$ : & $I_{\mathrm{obs}}>2 \sigma\left(I_{\mathrm{obs}}\right), 1290$ \\
\hline$N(\text { param })_{\text {refined }}:$ & 98 \\
\hline Programs: & $\begin{array}{l}\text { Bruker [1, 6], SHELX [2], } \\
\text { WinGX/ORTEP [3], Mercury [4], } \\
\text { PLATON [5] }\end{array}$ \\
\hline
\end{tabular}

Table 2: Fractional atomic coordinates and isotropic or equivalent isotropic displacement parameters $\left(\AA^{2}\right)$.

\begin{tabular}{lrrrr}
\hline Atom & $\boldsymbol{x}$ & $\boldsymbol{y}$ & $\boldsymbol{z}$ & $\boldsymbol{U}_{\text {iso }}{ }^{*} \boldsymbol{U}_{\text {eq }}$ \\
\hline F1 & $0.2083(2)$ & $0.49910(11)$ & $0.54795(10)$ & $0.0461(3)$ \\
F2 & $0.9445(2)$ & $0.63057(11)$ & $0.30789(10)$ & $0.0438(3)$ \\
O1 & $0.5649(2)$ & $0.68580(11)$ & $0.48661(11)$ & $0.0350(3)$ \\
H1 & $0.711(6)$ & $0.723(3)$ & $0.484(2)$ & $0.059(7)^{\star}$ \\
C1 & $0.5775(3)$ & $0.56673(14)$ & $0.42963(12)$ & $0.0263(3)$ \\
C2 & $0.3940(3)$ & $0.46969(15)$ & $0.46046(13)$ & $0.0306(3)$ \\
C3 & $0.3923(4)$ & $0.34802(15)$ & $0.40540(16)$ & $0.0371(4)$ \\
H3 & $0.267(5)$ & $0.286(2)$ & $0.428(2)$ & $0.051(6)^{\star}$ \\
C4 & $0.5833(4)$ & $0.32147(16)$ & $0.31579(16)$ & $0.0389(4)$ \\
H4 & $0.591(5)$ & $0.235(2)$ & $0.271(2)$ & $0.052(6)^{\star}$ \\
C5 & $0.7712(4)$ & $0.41559(16)$ & $0.28131(14)$ & $0.0355(3)$ \\
H5 & $0.901(5)$ & $0.401(2)$ & $0.223(2)$ & $0.049(6)^{\star}$ \\
C6 & $0.7636(3)$ & $0.53635(13)$ & $0.33867(13)$ & $0.0291(3)$ \\
\hline
\end{tabular}

by repeated melting and freezing of the compound in a fridge around $0{ }^{\circ} \mathrm{C}$.

\section{Experimental details}

All $\mathrm{H}$ atoms were located on a difference map and refined freely.

\section{Comment}

Phenol and derivatives are interesting bonding partners for a variety of transition metals and elements from the $p$-block. 
They can act as neutral or - upon deprotonation - as anionic ligands. Upon variation of the substituents on the aromatic system, a seemingly endless series of symmetric as well as asymmetric phenol derivatives featuring different steric pretenses and acidities of the hydroxyl-group are available. For phenol and phenolate, all bonding modes from monodentate (e.g. towards beryllium [7]) via bidentate (e.g. towards tin [8]) and tridentate (e.g. towards zinc [9, 10]) to tetradentate (e.g. towards sodium [11]) have been observed and secured on grounds of structural studies. Elucidating the coordination behaviour of various phenol in dependence of $\mathrm{pH}$-value and substitution pattern it seemed of interest to determine the crystal structure of the title compound to enable comparisons with metric parameters in envisioned coordination compounds. Recently, the molecular and crystal structures of 2-hydroxy-5-methylisophthalaldehyde [12], 3,5-dimethylphenol [13], 2,3,4,5,6-pentabromophenol [14] and 4-ethylphenol [15] have been determined. The structures of 2,6-dichlorophenol [16] and 2,6-diiodophenol in a co-crystal [17] are apparent in the literature next to the structure of the title compound co-crystallized with a 4-alkoxystilbazole [18].

The title compound is the difluorinated derivative of phenol bearing the two fluoro substituents in the two ortho positions to the hydroxyl group. The two $\mathrm{C}-\mathrm{F}$ bond lengths vary slightly with values of 1.3514(17) $\AA$ and 1.3634(16) $\AA$. Both values are in good agreement with compounds featuring fluorinated phenyl groups whose metrical parameters have been deposited with the Cambridge Structural Database [19]. $\mathrm{C}-\mathrm{C}-\mathrm{C}$ angles cover a range of $116.65(12)-122.75(14)^{\circ}$ and $122.78(14)^{\circ}$ with the smallest angle found on the carbon atom bearing the hydroxyl group and the largest two values invariably found on the carbon atoms bonded to the fluorine atoms.

In the crystal structure, the molecules are connected by means of cooperative hydrogen bonds. In terms of graph-set analysis [20], the descriptor for these hydrogen bonds - on the unary level - is $C_{1}^{1}(2)$. The molecules are connected to infinite chains along the crystallographic $a$ axis. $\pi$ stacking is not a prominent feature in the title structure with the shortest distance between two centers of gravity of 4.9287(11) A being in line with the length of the $a$ axis of the unit cell.

Acknowledgments: The corresponding author thanks the National Research Foundation for financial support.

Author contribution: All the authors have accepted responsibility for the entire content of this submitted manuscript and approved submission.

Research funding: None declared.
Conflict of interest statement: The authors declare no conflicts of interest regarding this article.

\section{References}

1. Bruker. APEX2; Bruker-AXS Inc.: Madison, Wisconsin, USA, 2012.

2. Sheldrick G. M. A short history of SHELX. Acta Crystallogr. 2008, A64, 112-122.

3. Farrugia L. J. WinGX and ORTEP for windows: an update. J. Appl. Crystallogr. 2012, 45, 849-854.

4. Macrae C. F., Bruno I. J., Chisholm J. A., Edgington P. R., McCabe P., Pidcock E., Rodriguez-Monge L., Taylor R., van de Streek J., Wood P. A. Mercury CSD 2.0 - new features for the visualization and investigation of crystal structures. J. Appl. Crystallogr. 2008, 41, 466-470.

5. Spek A. L. Structure validation in chemical crystallography. Acta Crystallogr. 2009, D65, 148-155.

6. Bruker. SADABS; Bruker-AXS Inc: Madison, Wisconsin, USA, 2008.

7. Arrowsmith M., Hill M. S., Kociok-Köhn G., MacDougall D. J., Mahon M. F., Mallov I. Three-coordinate beryllium $\beta$-diketiminates: synthesis and reduction chemistry. Inorg. Chem. 2012, 51, 13408-13418.

8. Yasuda H., Choi J.-C., Lee S.-C., Sakakura T. Structure of dialkyltin diaryloxides and their reactivity toward carbon dioxide and isocyanate. J. Organomet. Chem. 2002, 659, 133-141.

9. Boersma J., Spek A. L., Noltes J. G. Coordination complexes of bis(2,2-dimethyl-3,5-hexanedionato) zinc with organozinc-oxygen and -nitrogen compounds. crystal structure of the complex formed with phenylzinc phenoxide. J. Organomet. Chem. 1974, 81, 7-15.

10. Enthaler S., Eckhardt B., Inoue S., Irran E., Driess M. Facile and efficient reduction of ketones in the presence of zinc catalysts modified by phenol ligands. Chem. Asian J. 2010, 5, 2027-2035.

11. Kunert M., Dinjus E., Nauck M., Sieler J. Structure and reactivity of sodium phenoxide - following the course of the Kolbe-Schmitt reaction. Chem. Ber. 1997, 130, 1461-1465.

12. Habarurema G., Gerber T. I. A., Hosten E., Betz R. Redetermination of the crystal structure of 2,6-diformyl-4-methylphenol, at $200 \mathrm{~K}$ $\mathrm{C}_{9} \mathrm{H}_{8} \mathrm{O}_{3}$. Z. Kristallogr. NCS 2014, 229, 331-332.

13. Betz R., McCleland C., Marchand H. Redetermination of 3,5-dimethylphenol. Acta Crystallogr. 2011, E67, 01152.

14. Betz R., Klüfers P., Mayer P. 2,3,4,5,6-Pentabromophenol. Acta Crystallogr. 2008, E64, 01921.

15. Betz R., Klüfers P., Mayer P. 4-Ethylphenol. Acta Crystallogr. 2009, E65, 0544.

16. Bavoux C., Michel P. Structure cristalline du dichloro-2,6 phenol. Acta Crystallogr. 1974, B30, 2043-2045.

17. Trokowski R., Akine S., Nabeshima T. Remarkably selective recognition of iodobenzene derivatives by a macrocyclic bisPt"metallohost. Chem. Eur J. 2011, 17, 14420-14428.

18. Wong J. P.-W., Whitwood A. C., Bruce D. W. Hydrogen-bonded complexes between 4-alkoxystilbazoles and fluorophenols: solid-state structures and liquid crystallinity. Chem. Eur J. 2012, 18, 16073-16089.

19. Allen F. H. The Cambridge structural database: a quarter of a million crystal structures and rising. Acta Crystallogr. 2002, B58, 380-388.

20. Bernstein J., Davis R. E., Shimoni L., Chang N.-L. Patterns in hydrogen bonding: functionality and graph set analysis in crystals. Angew Chem. Int. Ed. Engl. 1995, 34, 1555-1573. 